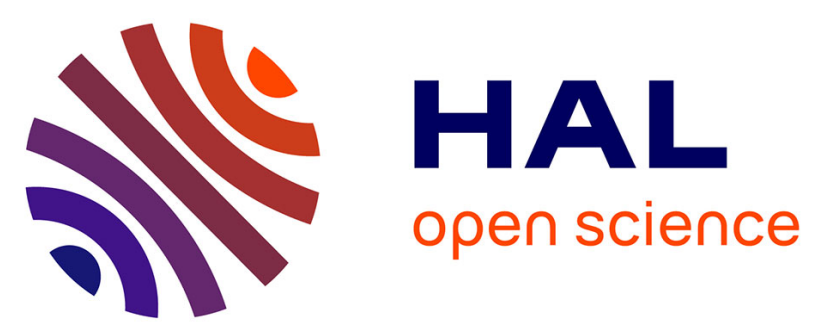

\title{
Memory functioning 7 years after severe childhood traumatic brain injury: Results of the Traumatisme Grave de l'Enfant study
}

Hugo Câmara-Costa, Solène Viot, Leila Francillette, Marion Opatowski, Hanna Toure, Dominique Brugel, Anne Laurent-vannier, Philippe Meyer, Laurence Watier, Georges Dellatolas, et al.

\section{To cite this version:}

Hugo Câmara-Costa, Solène Viot, Leila Francillette, Marion Opatowski, Hanna Toure, et al.. Memory functioning 7 years after severe childhood traumatic brain injury: Results of the Traumatisme Grave de l'Enfant study. Journal of neuropsychology, 2021, 10.1111/jnp.12247 . hal-03205426

\section{HAL Id: hal-03205426 \\ https://hal.sorbonne-universite.fr/hal-03205426}

Submitted on 22 Apr 2021

HAL is a multi-disciplinary open access archive for the deposit and dissemination of scientific research documents, whether they are published or not. The documents may come from teaching and research institutions in France or abroad, or from public or private research centers.
L'archive ouverte pluridisciplinaire HAL, est destinée au dépôt et à la diffusion de documents scientifiques de niveau recherche, publiés ou non, émanant des établissements d'enseignement et de recherche français ou étrangers, des laboratoires publics ou privés.

$$
\text { Copyright }
$$




\section{Memory functioning 7 years after severe Childhood Traumatic Brain Injury: Results of the Traumatisme Grave de l'Enfant (TGE) study}

Câmara-Costa Hugo ${ }^{1,2}+$, Viot Solène ${ }^{3,4}$, Francillette Leila ${ }^{1}$, Marion Opatowski ${ }^{5}$, Toure Hanna ${ }^{3}$, Brugel Dominique ${ }^{3}$, Laurent-Vannier Anne ${ }^{3}$, Meyer Philippe ${ }^{6,7}$, Watier Laurence ${ }^{5}$, Dellatolas Georges $^{2}$, Chevignard Mathilde $1,2,3$

1 Sorbonne Université, CNRS, INSERM, Laboratoire d'Imagerie Biomédicale (LIB), F-75006, Paris, France

2 Sorbonne Université, GRC 24 Handicap Moteur Cognitif et Réadaptation (HaMCre), AP-HP, F-75013, Paris, France

3 Rehabilitation Department for Children with Acquired Brain Injury, and Outreach team for Children and Adolescents with Acquired Brain Injury; Hôpitaux de Saint Maurice, Saint Maurice, France

4 Physical and Rehabilitation Medicine Unit, Bordeaux University Hospital, Bordeaux, France

5 Biostatistics, Biomathematics, Pharmacoepidemiology and Infectious Diseases (B2PHI), INSERM. UVSQ, Institut Pasteur, Université Paris-Saclay, Paris, France

6 Pediatric Anesthesiology Department, Hôpital Necker Enfants Malades, Paris, France

7 Faculté de Médecine René Descartes Paris 5, Paris, France

Corresponding author: Hugo Câmara-Costa, Sorbonne Université, Laboratoire d'Imagerie Biomédicale (LIB), Service de Médecine Physique et Réadaptation, Hôpital de la Pitié Salpétrière, 47 boulevard de l'hôpital, 75013 Paris. Tel.: +33(0)646534466.

Email: hugocamaracosta@gmail.com

Running head: Memory 7-years after severe childhood TBI 


\section{Data availability statement}

Due to legal and ethical imperatives in France, the data used in the analyses of the present study cannot be shared or made publicly available.

\section{Acknowledgments}

The initial data collection for the initiation of the cohort study was funded by the Département de la Recherche Clinique et du Développement, AP-HP (Paris, No. PHRC 2003; AOM 03018). The 7-year follow-up study was funded by a co-funding by the French Ministry of Health's general direction of health and direction of research, studies, assessment and statistics, by the national fund for health insurance of salaried workers, the national fund for health insurance of independent workers, by the national fund for solidarity and autonomy and by the national institute for prevention and education for health, in the call for research projects launched by the IReSP in 2011. In depth analyses and manuscript preparation were also funded by two grant(s) awarded to Hugo Câmara-Costa: one grant from the French Speaking Society of Research in Children with Disabilities (SFERHE, www.sferhe.org) and one joint grant from the French Traumatic Brain Injury Society (France Traumatisme Crânien - FTC) and the French Speaking Society of Physical Medicine and Rehabilitation (SOFMER, www.sofmer.com).

\section{Declaration of interest}

The authors report no conflict of interest. 


\begin{abstract}
Objective: to explore memory functioning 7-years after severe pediatric TBI, associated factors, and relationships with other outcomes.

Method: Children aged $0-15$ years $(n=65)$, consecutively admitted over a 3 -year period in a single trauma center, who survived after severe non-inflicted TBI, were included in a prospective longitudinal study. Memory assessments were performed 7-years post-injury using the Children's Memory Scale (CMS) or the Wechsler Memory Scale (WMS IV), according to age. The General Memory Score (GMS-7) was the primary outcome.

Results: Thirty-seven patients were available for assessment at 7-years post-injury. Mean GMS-7 was in the low average range $(M=84.9, S D=12.1)$. Lower $\mathrm{GMS}-7$ was significantly associated with markers of higher injury severity, such as length of coma. One-year post-injury functional and disability outcomes explained 74\% of the variance of GMS-7. Concurrent intellectual ability and type of ongoing education correlated strongly with GMS-7. Age at injury and parental education were not associated with memory outcome.

Conclusions: Memory functioning is variable but often strongly impaired several years after severe pediatric TBI, and is mostly related to injury severity, functional outcomes measured 1year post-injury, and concomitant cognitive and educational outcomes. GMS-7 was lower at 7years than one-year post-injury, supporting the importance of long term follow-up.
\end{abstract}

Keywords: severe traumatic brain injury, memory, longitudinal cohort study, child, adolescent, long term follow-up. 


\section{Memory functioning 7 years after severe Childhood Traumatic Brain Injury: Results of the Traumatisme Grave de l'Enfant (TGE) study}

Traumatic brain injury (TBI) is a leading cause of mortality and long-standing disability in children and a substantial contributor to the health resource burden [1]. TBI is conceptualized as a chronic health condition, which can have lifelong and dynamic effects on health and well-being [2,3]. Annual worldwide incidence of childhood TBI varies greatly by country, with most reporting 47 to 280 per 100,000 children, and maximum figures estimated at 691 per 100 000, with $3-15 \%$ of severe injuries [4,5].

Severe pediatric TBI, defined by a Pediatric Glasgow Coma Scale (Peds-GCS) score $\leq 8$ [6], is associated with long-standing neurological, neuropsychological and behavioral impairments, such as sensory-motor deficits, including hemiparesis and cerebellar dysfunction [7], and deficits in language, visual-spatial skills, processing speed, memory, attention, working memory, executive functioning and behavior regulation [8-13]. Those deficits are associated with impaired educational achievement [12,14-17], reduced participation, and impaired quality of life in the long term [18-21].

Memory, defined as the persistence of learned information over time allowing its appropriate subsequent reuse, is a complex and dynamic process, divided into four stages: encoding, storage, consolidation and recall. Each stage is involved in the visual and verbal modalities, and interacts with other cognitive functions, such as intellectual ability, attention, and executive functions $[11,16]$, and can be explored by immediate and delayed memory tasks. Memory develops throughout childhood and adolescence and is essential for new learning and academic achievement. A sequential process for the development of memory has been described, from procedural and implicit memory to episodic and explicit memory [22]. In accordance with this, 
Lah and colleagues [23] reported both implicit and explicit memory deficits after severe TBI occurring before 6 years of age, but preserved implicit memory in children who sustained severe TBI during late childhood.

Severe TBI has been found to be responsible for lower performance in immediate and delayed verbal episodic memory [8,23,24], working memory and attention/concentration $[11,13,25,26]$ and episodic autobiographical memory [27]. Visual memory may be more resistant to severe TBI than verbal memory $[8,28]$. Long-term information retrieval seems to be more severely impaired, although all components of memory can be impacted (i.e. encoding, storage, consolidation, and retrieval) [9]. Memory complaints in daily life are extremely frequent after TBI and patients often report accelerated long-term forgetting, which may occur when any of the components of the brain networks involved in long-term memory formation, or their interaction, is disrupted [2733]. Those observations are supported by imaging studies, where hippocampal structure (especially hippocampal head volume) was found to be significantly correlated to injury severity, and to memory performance in the sub-acute phase of injury (6 weeks post-injury) [29]. Memory deficits after severe pediatric TBI interact with multiple other factors, such as language deficits, behavior problems, and other cognitive impairments [11,34,35].

Several factors are associated with worse memory outcomes following pediatric TBI, including TBI severity [8,36,37], younger age at injury in some studies [25,38], but not all (see [28] for a review), and older age at assessment [39]. Outcomes may also depend on an interaction between age at injury and severity, as the disease process that occurs following a pediatric TBI interacts with the trajectory of normal brain development $[8,40,41]$. Time since injury appears to be an important factor in cognitive and memory outcome after pediatric TBI, but its effect is probably nonlinear, because a possible initial improvement may not persist in the long-term. Previous studies have reported that some recovery occurs during the first year post-injury, but reaches a 
plateau after that time, with deficits still apparent at 2- to 4-years post-injury [40,42]. In the longterm, a meta-analysis by Dunning and colleagues [43] showed that longer time since injury was associated with greater decrements in verbal short-term memory and verbal working memory skills in child and adult survivors of moderate to severe TBI; these aspects of memory do not recover over time and instead, individuals might show increased rates of cognitive decline. The latter observation seems congruent with the idea that the effects of a brain injury during development may not become evident immediately after injury, but may appear later in longitudinal studies observing trajectories of development over time [28]. Other factors reported to be associated with worse memory functioning following childhood TBI include lower preinjury level of education, presence of pre-injury learning difficulties, lower pre-injury level of child's social abilities and lower socio-economic family background [37,44-46]. Finally, other authors suggested that lack of exposure to learning opportunities, or lack of medical treatments/procedures (including rehabilitation) are associated with negative cognitive outcomes $[8,44]$.

In a previous report of the TGE (Traumatisme Grave de l'Enfant, i.e. Severe Childhood Trauma) cohort (see description below), we presented memory outcomes over the first 2-years post-injury [12]. Memory impairment at 3-months post-injury was severe (mean one standard deviation below expected values), and improved significantly during the first two years post-injury. Attention/concentration and verbal memory were significantly more impaired than visual memory. Memory outcome was associated with parental education and markers of initial TBI severity, and correlated with other outcomes, such as intellectual ability, overall functional outcome, and type of post-injury education [12]. Further, prospective memory (e.g. "I can't remember what I have to do") was found to be significantly impaired in the same cohort 7-years 
post-injury using ecological experimental tasks [47], confirming findings of other investigations [48-50].

The primary aim of the present study was to explore memory functioning 7 years after severe pediatric TBI in the TGE prospective longitudinal cohort, and to examine whether the initial memory improvement at 3-, 12- and 24-months post severe TBI, reported in Viot et al. [12], persists in the long-term. We hypothesized that time since injury $(3,12,24$ months, and 7-years) after severe childhood TBI might be significantly associated with memory performance, with possible lower performance in the long term. The second aim was the exploration of associations of long-term memory performance with demographic and medical/severity factors, early assessment (1-year post-injury) of functional, cognitive and disability outcomes, and other concurrent outcomes 7-years post-injury: intellectual ability, educational status, overall disability, and self- and proxy questionnaire-reported executive functioning, behavior, quality of life, and fatigue. We hypothesized that greater injury severity, low parental education, poorer pre-injury functioning, younger age at injury, poorer 1-year post injury cognitive outcome, and some 7years post-injury concurrent outcomes (lower educational status and IQ) would be significantly associated with 7-years post-injury memory performance.

\section{METHODS}

The present work is part of a larger prospective longitudinal study (TGE cohort), aiming at determining overall and specific outcomes following severe childhood TBI [10,12,19,47,51-54]. The TGE study initiated at the Paris 5 University Hospital Necker-Enfants-Malades and the follow-up was conducted in the Rehabilitation Department for Children with Acquired Neurological Injury in the Saint Maurice Hospitals. 


\section{Patients}

Participants were children aged < 16 years consecutively admitted between January 2005 and December 2008 to the pediatric neurosurgical intensive care unit (ICU) of the Necker-EnfantsMalades Hospital within the first 6 hours following severe accidental TBI. Eighty-one children were included at the acute stage of TBI, defined as Glasgow Coma Scale (GCS) score $\leq 8$ [6] at admission and/or an Injury Severity Score (ISS) > 16 [55]. Causes of TBI were motor vehicle accidents and falls. Children with no vital signs upon admission, non-accidental head injury and a previous history of diagnosed neurological, psychiatric or learning disorders were not included. Sixteen patients died during the acute period, leaving 65 (80\%) children available for follow-up. All children received treatment according to international guidelines for the management of severe TBI in the pediatric neurosurgical ICU of a regional pediatric trauma center [56], and a large majority $(83 \%)$ required/received multidisciplinary rehabilitation after acute care. At 7-years post-injury, 26 of the 65 survivors were lost to follow-up or did not wish to participate, leaving 39 patients (60\%), aged 7-22 years, available for assessment. There was no significant difference among participants $(n=39)$ and non-participants $(n=26)$ regarding parental education, age at injury, markers of initial injury severity, or any of the 3, 12, or 24-months postinjury general and specific outcomes. Two patients did not complete the memory assessment, due to major fatigue and behavioral issues. Therefore, the analysis sample consisted of 37 participants who had available 7-years post-injury memory assessment data.

Follow-up after the acute stage of TBI through 7-years post-injury comprised comprehensive medical and neuropsychological assessments, performed by trained professionals at 3-months, and 1-, 2- and 7-years post-injury in the pediatric rehabilitation unit of the Saint-Maurice Hospitals. The neuropsychological assessments consisted of standardized tests and questionnaires evaluating intellectual ability, executive functioning and memory performance. 
In order to analyze evolution of memory over time, we considered the memory assessments performed at 3-, 12- and 24-monts post-injury, in addition to the 7-years assessments. Overall, a subsample of 22 patients (59\% out of 37) had undergone complete memory assessments at all four time-points (3-, 12-, 24-months and 7-post injury). Children who had available data on all the four time-points $(n=22)$ were significantly older at injury and at assessment than children who did not had available data on all the four assessments $(n=15)$. This age difference was mainly related to children who were younger than the age ( 5 years) required to complete the memory assessment at 3- or 12- or 24-months post-injury ( $\mathrm{n}=12)$, together with those who did not have available data on at least one of the assessments performed at 3- or 12- or 24-months post-injury $(\mathrm{n}=3)$. There were no significant differences between these groups regarding socio-demographic characteristics, parental education, pre-injury history, markers of initial injury severity and specific outcomes of interest (memory performance and intellectual ability 7-years post-injury).

Figure 1 shows the flowchart of participants who underwent age-appropriate memory assessments at each time point.

The study was approved by the ethics committee and all parents (or young adults with TBI, at the 7-years follow-up) gave their informed written consent at all stages of the study.

[INSERT FIGURE 1 HERE]

\section{Measures}

\section{Pre-injury history, age at injury, and socio-demographic characteristics 7-years post-injury}

We recorded the child's pre-injury educational history (e.g., if the child stayed back one year or had difficulty and/or extra help at school) and age at injury. We also collected information regarding the socio-demographic characteristics of the family 7-years post-injury, namely parental education level (medium/high: at least one parent graduated from high school vs. low: none of the parents reached high school graduation), family situation (child living with both 
biological parents $v s$. mono-parental of non-marital families) and family size (number of children in the household).

\section{Initial injury severity}

Initial injury severity was determined using three standard measures, namely the Pediatric Glasgow Coma Scale (GCS) score [6]; the Pediatric Trauma Score (PTS) [57], and the Injury Severity Score (ISS) [55]. Within this sample of children who all underwent severe TBI, who were all intubated and ventilated, length of coma (in days), was used as a quantitative marker of injury severity. To resolve eventual fluctuations of the GCS score, we used the minimal GCS score observed over the first 24 hours.

\section{Injury-related characteristics}

We also collected the following medical data during the acute phase in the intensive care unit: intracranial pressure, minimal brain perfusion pressure, collapses, occurrence of immediate and/or early seizures, and presence of a penetrating skull fracture.

\section{Outcome measures collected during follow-up 1-year post-TBI}

Overall level of disability: Glasgow Outcome Scale modified for children (GOS-Peds; [58]). Motor deficits: Neurological assessment allowed collecting information relative to the presence or absence of (1) motor deficit (e.g., hemiplegia or hemiparesis) and/or (2) signs of cerebellar dysfunction (ataxia and / or coordination disorders). We defined presence of motor deficits as the presence of at least one of the above.

Post-injury type of education: We defined type of education in two categories: mainstream education in general classrooms without adaptation, help or grade retention $v s$. specialized education, or general education with adaptation and/or help and/or grade retention.

Functional outcome: The Pediatric Injury Functional Outcome Scale (PIFOS [59]) was completed by a trained health care provider during a structured interview with parents. This scale 
assesses functional outcome in relation to pre-injury levels of functioning across six domains (motor, daily living, communication skills, social-emotional, cognition/academic functioning, and physical changes). Ratings of each of the 26 items follow a four-point Likert scale ( 0 , no change from pre-injury levels; 2 to 4, increasing need for support and significant functional limitations), higher PIFOS scores indicating greater difficulties (range of total raw scores [0-104]).

Intellectual functioning: Full-Scale Intellectual Quotient (FSIQ) and its component indices was assessed using the age-appropriate French versions of the Wechsler Intelligence Scale for Children (WISC-III [60]) and Wechsler Preschool and Primary Scale of Intelligence (WPPSI-III [61]).

Memory: General memory 1-year post-injury was assessed using the Children's Memory Scale (CMS [62,63]) for children aged between 5 years and <16 years.

\section{Outcome measures collected 7-years post-TBI}

\section{Clinician-rated measures}

Overall disability: The GOS-Extended [58] and the GOS-Extended Pediatric version [64] were used to assess overall disability in a more refined way. These validated structured interviews assess TBI outcome in children, adolescents and adults. The outcome scores were ranked according to eight categories: 1=Upper Good Recovery, 2=Lower Good Recovery, 3=Upper Moderate Disability, 4=Lower Moderate Disability, 5=Upper Severe Disability, 6=Lower Severe Disability, 7=Vegetative State and 8=Death.

Motor deficits: as at 1-year post-injury

Ongoing education: as at 1-year post-injury. 


\section{Performance-based outcomes 7-years post-injury}

\section{Main outcome: memory assessment}

Memory was assessed in children aged between 5 years and $<16$, using the Children's Memory Scale (CMS [62]), and the French version of the Wechsler Memory Scale Fourth-Edition (WMS-

IV [65]) for those aged 16 years and above [12].

The CMS provides eight standardized index scores [mean score 100 ( $\mathrm{SD}=15)$ ]. Only five scores were used in the present study: Verbal Immediate and Delayed Memory, Visual Immediate and Delayed Memory and a General Memory Score (GMS). The GMS is based on the sum of the standardized scores obtained in the four Immediate and Delayed conditions of the Verbal and Visual memory index scores. Each of the four memory index scores are based on the sum of the standard scores from four subtests, two verbal ("Stories", "Word pairs"), and two visual ("Dot location", and "Faces"), both in their immediate and delayed conditions.

- "Stories": the child is required to listen to a short story, and to recall it with as many details as possible, immediately and at $25-35 \mathrm{~min}$, and then answer questions about it;

- "Word pairs": after a learning phase, a list of matched words is presented orally to the child. In the immediate recall, the child is then asked to recall the second word of the pair after the first word of the pair is presented. In the delayed recall, the child is asked to recall as many of the word pairs that were presented previously, and to recognize the word pairs previously learned among a new list of word pairs;

- "Dot location": After a learning trial, the child is asked to recall the position of blue chips inside a predawn grid in an immediate and a delayed recall;

- "Faces": the child is asked to recognize a series of faces previously presented to her in an immediate and a delayed recognition condition. 
The CMS has robust psychometric properties, such as good internal consistency (Cronbach alpha $=0.88$ to 0.93 ), good inter-rater reliability ( 0.98 or above) and good discriminant validity.

However, test-retest allows gains of up to $1 \mathrm{SD}$ when assessment is repeated.

The Wechsler Memory Scale (for those aged 16 years or above) provides five index scores [mean score $100(\mathrm{SD}=15)$ ], different from those of the CMS (Immediate Memory, Delayed Memory, Visual Working Memory, Auditory Memory, and Visual Memory). However, the WMS-IV, as well as the CMS, includes two verbal subtests (Logical Memory and Verbal Paired Associates), and two visual subtests (Designs and Visual Reproduction) allowing assessment of immediate and delayed verbal and visual memory.

- "Logical Memory I and II": Two short stories (4-5 lines) were presented orally to participants, who were then asked to recall as many details about the story immediately after hearing it (I Immediate recall), or after a 30-35 minutes interval (II Delayed recall). Participants were also asked yes/no questions about the story content to test recognition.

- "Verbal Paired Associates I and II": A list of 10 or 14 pairs of words (four trials of the same list presented in different order) was orally presented to participants. They were then asked to recall the corresponding word after the examiner read the first word of each pair immediately after the presentation of each list (I Immediate recall), or after a 20-30 minutes delay (II Delayed recall). Participants were also read a list of pairs of words and asked to identify if each pair belonged to the previous lists or if it corresponded to a new word pair.

- "Designs I and II": A grid with 4-8 designs on a page was presented to participants, who were then asked to select the designs from a set of cards and to place the cards in a grid in the same place as showed initially (I Immediate recall). Subsequently, participants were requested to recreate the pages shown in the immediate condition with the cards and grid (II Delayed 
condition). Participants were also asked to select from a series of grids the two designs that were correct and in the same place with respect to the immediate condition.

- "Visual Reproduction I and II": A series of five designs was shown to the participants (one at a time), who were then asked to draw the design from memory immediately after its presentation (I Immediate recall), or in a delayed condition (II Delayed recall). Participants were also requested to choose the original designs of the immediate condition from six designs presented on a page.

In order to allow comparison of general memory scores across the sample, we calculated the same four index scores as for the CMS, as well as a General Memory Score (GMS). We calculated a Verbal Immediate Memory partial score by summing and averaging the standard scores of the Logical Memory I and Verbal Paired Associates I subtests, and a Verbal Delayed Memory based on the Delayed recall conditions of the same subtests. Similarly, we computed a Visual Immediate and Delayed Memory index score based on the Immediate and Delayed conditions of the Designs and Visual Reproduction subtests, respectively. The GMS corresponded to the averaged sum of all the four index scores. The computation of this score was justified by two criteria: 1) similar general mean scores between the CMS and the WMS; and 2) good internal consistency according to the Cronbach alpha of the WMS Cronbach (alpha=.90), given the strong correlations observed between the four index scores (Pearson $r>.70$ ). From the 37 participants who underwent memory assessments 7-years post-injury, 20 were assessed with the CMS (<16 years), and 17 with the WMS-IV ( $\geq 16$ years). From these 37 participants, a subsample of 22 participants had also performed memory assessments at 3-, 12and 24-monts post-injury, in addition to the 7-years assessments. All the participants of this subsample were assessed with the CMS at 3-, 12- and 24-monts post-injury. At 7 years-post injury, six participants were assessed with the CMS (<16 years) and 16 with the WMS-IV. There 
were no differences in the general memory scores at 3-, 12- and 24-monts post-injury, as well as at 7 years-post injury, between participants assessed with the CMS or the WMS 7-years postinjury.

Intellectual ability was measured through age-appropriate French versions of the Wechsler Intelligence scales, namely the Wechsler Intelligence Scale for Children up to 15 years (WISCIV [66]) and the Wechsler Adult Intelligence Scale IV (WAIS-IV [67]) for those aged 16 or above. Those scales provided four domain indices (Verbal Comprehension Index, Perceptual Reasoning Index, Working Memory Index, Processing Speed Index), and a Full-Scale Intellectual Quotient (FSIQ), (mean 100; SD=15).

Questionnaire-based outcomes 7-years post-injury

Executive functioning: We used the French versions of the Behavior Rating Inventory of Executive Functions (BRIEF [68,69]). Age-appropriate self- (age 18 years or above) and parentreport (all ages) forms allowed calculating two composite indices and a total index score (Behavior Regulation Index, Metacognitive Index and Global Executive Composite, respectively). Higher T-scores (mean $[\mathrm{SD}]=50$ [10]) indicate worse executive functioning (more complaints).

Behavior: We used self- and parent-reports versions of the Achenbach's questionnaires, namely the Children's Behavior Checklist (ages 4-18 years), Youth Self-Report (ages 11-18 years), Adult Behavior Checklist, and Adult Self-report (ages > 18 years) [70,71]. We computed three summary index scores (Internalizing problems, Externalizing problems and Total problems). Higher age standardized T-scores $(\mathrm{Mean}=50, \mathrm{SD}=10)$ indicate more behavior problems. Health-Related Quality of Life (HRQoL): We used the Pediatric Quality of Life Inventory (PedsQL) for children (age 2-17 years) [72] and young adults (age 18-25 years) [73]. Age appropriate versions of French-validated self- and parent/proxy report forms (23 items) allowed 
us to compute a total HRQoL Score, with lower scores (range: 0 to 100) indicating lower HRQoL.

Fatigue: We used the Pediatric Quality of Life Inventory (PedsQL) Multidimensional Fatigue Scale (MFS) [74,75]. Self- and parent-report forms of this 18-item inventory were used to assess symptom-specific fatigue in children (ages 2-17 years) and young adults (ages 18-25 years). We computed a total score expressed in a 0 - to 100-point scale, with lower scores indicating higher fatigue levels.

Family Assessment device (FAD): This self-report questionnaire assesses family functioning over six domains (Problem Solving, Communication, Roles, Affective Responsiveness, Affective Involvement, and Behavioral Control), and previous research has reported usefulness of the FAD as a measure of family functioning in clinical and non-clinical samples [76,77]. In the present study, parents completed the 12-item short form of the French version and rated each item on a four-point scale ranging from 1 (strongly agree) to 4 (strongly disagree). The total score is the quotient between the sum of the items' ratings and the total number of items, after reversing the negatively worded items. Scores range from 1 to 4 and higher scores indicate worse family functioning.

\section{Data analysis}

We used the descriptive statistics procedures from the SAS ${ }^{\circledR}$ software version 9 (Statistical Analysis Software, Cary, NC) to examine socio-demographic, injury severity and post-injury characteristics 1- and 7-years after severe TBI. In order to test the hypothesis that time since injury (3, 12, 24 months, and 7-years) after severe childhood TBI might be significantly associated with memory performance 7-years post-injury, we examined the evolution of the general memory score from 3 months to 7-years post-injury was using repeated measures ANOVA. 
To examine the hypothesis that injury severity, low parental education, pre-injury functioning, 1year post injury cognitive outcome, and some 7-years post-injury concurrent outcomes (educational status, IQ) would be significantly associated with memory performance 7-years post-injury, we used $t$-tests, ANOVA, and Pearson correlations, and regression analyses (GLM procedure of SAS). Statistical significance was set at the $p<0.05$ level.

\section{RESULTS}

\section{Description of the study sample}

\section{Demographic and injury severity data (Table 1)}

Table 1 describes the socio-demographic information and the initial injury characteristics for the study participants ( $n=37 ; 62 \%$ males). About half of the participants were from a medium-high parental education background and five children had required help at school or had stayed back one year before their injury (14\%). Mean age at injury was 7 years (ranging from 3 months to 14 years). Mean length of coma was 6.5 days (ranging from 1 to 22 days). At the 7-years post-injury time-point, mean age at assessment was 15 years (ranging from 7 to 22 years), and 13 patients (35\%) had reached adult age ( $\geq 18$ years).

\section{Overall outcomes at 1-year and 7-years post-injury (Table 1)}

From 1-year to 7-years post-injury the proportion of patients with severe disability (32\% and $19 \%$, respectively), and motor impairment (35\% and 22\%) decreased. Mean overall intellectual ability (FSIQ) was lower than expected (i.e. 100, $p<.0001$ ) at both time points (88.9 and 86.4), with very high variability (range $40-129$ at 7-years post-injury). At 7-years post-injury, 17 (47\%) children scored $<85$, and $4(11 \%)$ were in the disability range $(<70)$ for FSIQ.

[INSERT TABLE 1 HERE] 


\section{Memory assessment at 7-years post-TBI (Table 2)}

Table 2 presents the mean scores for the five memory indices, according to the age group and the scale used to assess memory 7-years post-injury [CMS for the younger age group $(n=20)$ and WMS-IV for the older age group $(n=17)])$. There were no significant differences in the general memory score (GMS) according to the age group $(t(35)=.01, p=.99)$. However, verbal memory scores tended to be lower than visual memory scores with the CMS (in the younger participants), and the opposite pattern was observed with the WMS-IV (in the older participants). The visual delayed memory score was significantly lower in the older age group (WMS-IV) than in the younger group $(\mathrm{CMS})(t(35)=5.05, p<.001)$. In the subsequent analyses, we thus considered exclusively the general memory score.

\section{[INSERT TABLE 2 HERE]}

\section{Evolution of memory over time}

Twenty-two participants (65\%) had available CMS scores at 3-months, 1-year, 2- and 7-years post-injury (i.e. were old enough (at least 5 years) to be assessed at 3-months post-injury). There was an overall tendency of GMS to increase between 3- and 12-months $(F(1,21)=10.19$, $p=.0044)$ and 12- and 24-months $(F(1,21)=4.34, p=.049)$, with a significant decline between 24months and 7-years post-injury $(F(1,21)=36.9, p<.0001)$ (Figure 2a). Individual scores showed that GMS increased between 3 and 12 months post-injury for a majority of participants. Evolution of GMS was more variable from 12 to 24 months post-injury. Variability of the scores was high at 24 months. GMS decreased between 24 months and 7-years post-injury for a large majority of participants, especially when GMS at 24 months was high. At 7-years post-injury, no participant obtained a high GMS (i.e. $\geq 120$ ), and the mean GMS was very similar to the measures performed 3 months post-injury (Figure 2b). Actually, GMS at 7-years post-injury did not differ significantly from the score measured at 3-months post-injury 
$(F(1,21)=1.01, p=0.32)$. These analyses were also performed after excluding the four participants exhibiting FSIQ scores in the disability range $(<70)$, and results remained unchanged.

[INSERT FIGURE 2 a \& b HERE]

Associations of the general memory score at 7-years post-injury with socio-demographic factors, injury characteristics, and early (1-year post-injury) outcomes (Table 3).

Associations of GMS with socio-demographic or pre-injury factors (gender, parental education, family situation and size, or presence of pre-injury school difficulties) and with injury-related characteristics other than severity (intracranial hypertension, brain hypo-perfusion, collapses, seizures, penetrating skull fracture) did not reach significance. The mean general memory score of the five patients who presented pre-injury school difficulties was lower than in the rest of the group ( $n=32)$, but this difference failed to reach statistical significance $(\mathrm{M}=77.3, \mathrm{SD}=16.8$ vs. $\mathrm{M}=85.4, \mathrm{SD}=13.5, p=.24)$. As seen in Table 3, low GMS was associated with increased TBI severity (specifically lower Injury Severity Score and higher length of coma), as well as with 1year post-injury outcomes, namely: increased overall disability according to the GOS (Figure 3), poorer functional outcome (PIFOS), lower intellectual ability (FSIQ) and poorer general memory score (GMS).

A regression analyses showed that 1-year post-injury outcomes (GOS, FSIQ, motor deficits, PIFOS, and general memory score) explained $74 \%$ of the variance of 7 -years post-injury general memory score, with overall disability (GOS-Peds) as the strongest predictor (Table 4). Inclusion of initial severity indices (length of coma, ISS) did not significantly increase the amount of variance explained.

[INSERT TABLE 4 HERE] 
Associations of the general memory score at 7-years post-injury with concurrent outcomes (Tables 5 and 6)

The GMS 7-years post-injury was significantly associated with ongoing type of education $(\mathrm{Mean}(\mathrm{SD})=88.48(14.68)$ and 78.75(11.29) for Mainstream without adaptation or delay versus Specialized-adapted-delayed education, respectively), and with all the Wechsler scales indices (FSIQ, VIQ, PIQ, WMI and PSI).

Regarding the concurrent questionnaire-based measures, lower GMS 7-years post-injury was associated with increased parental reports of externalizing problems, and increased self-reported complaints of executive functioning. There were no other significant associations between general memory and the remaining questionnaires assessing HRQoL (PedsQL), Fatigue (MFS), and family functioning (FAD).

\section{DISCUSSION}

This study aimed to assess memory seven years after severe childhood TBI, and to determine demographic, medical and severity factors associated with memory performance and recovery over time. We report memory outcomes in a relatively large sample of children who underwent comprehensive extended medical and neuropsychological follow-up after severe TBI. Overall, results indicate relatively severe outcomes (although we observed high variability in the outcomes), with decreased intellectual ability, and relatively high proportions of children requiring school adaptations, extra help, or special education. Among factors influencing outcome, memory function was mostly associated with markers of injury severity, and it was associated with other post-injury outcomes such as intellectual ability, level of disability and educational outcome.

Our results confirm the hypothesis that time since injury after severe childhood TBI was significantly associated with 7-years post-injury memory performance. Mean memory 
performance was low at 3 months post-injury, showed a significant improvement during the first year, a marginal improvement during the second year, and a strong decline between 2- to 7-years post-injury, reaching about the same level as at 3 months post-injury (around one standard deviation below expected values). The overall pattern of our results is congruent with the conclusions presented in the meta-analysis of Dunning et al. (2016), in which greater decrements in working memory skills were associated with longer time post-injury, despite initial improvement. This decline on the long-term might be associated with a decreased rate of memory progression in children with TBI compared with typically developing children, due to difficulties developing or acquiring new skills. Ultimately, failure in reaching the appropriate cognitive building blocks might result in impairments and difficulties that extend beyond those seen at the time of injury and suggest a pattern of emerging deficits rather than a recovery over time. Furthermore, previous research [12] has advanced the argument that the improvement observed between 3-, 12 and 24- months post-injury could be partly related to test-retest effects (estimated up to $1 \mathrm{SD}$ according to the CMS manual), which might have cease to contribute to memory performance 7-years post-injury due to the longer delay between assessments. Applied to our results, we hypothesize that the absence of the test-retest effect coupled with the lack of progress at the expected rate probably might have contributed to the magnitude of this overall trajectory In the present study, the discrepancy between verbal and visual memory was scale-dependent, with better visual memory using the CMS, contrasting with better verbal memory using the WMS-IV. The difference was particularly strong for visual delayed memory, where $47 \%$ of the participants obtained scores < -2SD with the WSM-IV, versus $10 \%$ with the CMS. A possible explanation for this pattern of results is that the "visual memory" subtests are very different in the two scales: dot localization and face recognition for CMS, design memory-localization and figure reproduction for WMS-IV. The visual memory subtests in the WMS are particularly complex, 
requiring active recall, and they have little in common with the face recognition task proposed in the CMS. Following TBI, recognition is often more preserved, while active recall tends to be more impaired. This could explain why visual memory tended to be higher in patients assessed with the CMS, when compared to those assessed with the WMS, who were asked to provide active recall of relatively complex figures. On the other hand, the lower verbal memory scores observed in the CMS could be related to the complexity and difficulty of the "Stories" subtest (when compared to that of the WMS), as noticed by clinicians who use them regularly. However, the general memory score was similar between the CMS and the WMS-IV, which allowed pooling the observations. This important issue of outcome measurement should be considered in the development of future assessments of memory function, especially in pediatric populations followed longitudinally. Memory assessment could be enhanced by the development of more appropriate and consistent scales according to larger age ranges, which should comprise subtests assessing comparable memory constructs in order to allow comparisons across several age spans. Our results also confirmed to some extent our hypothesis regarding the factors related to the memory outcomes 7-years post-injury. The general memory score was mostly influenced by initial TBI severity measures (i.e. ISS and length of coma), similar to findings of other studies $[13,25,45,78]$, and consistent with the results of the initial follow-up of the same cohort over 24 months [12]. The strong and persistent effect of injury severity measures, probably reflecting the presence of diffuse brain injury, on cognitive skills including memory function has repeatedly been reported (see [8,28], for literature reviews). This injury severity effect is still present 7-years post-injury, even though all patients are in the severe spectrum of injury, as also previously reported for anterograde and autobiographical memory [24,27], verbal memory and visual memory [8] or prospective memory [47]. The other initial injury characteristics were not 
associated with memory outcomes at 7-years post-injury, similarly to findings in the initial follow-up of the TGE cohort [12].

None of the demographic or pre-injury factors (e.g., age at injury, pre-injury difficulties at school) were related to 7-years memory outcome. This is somewhat surprising, as pre-injury functioning has been reported to predict subsequent outcomes following childhood TBI $[79,80]$, despite the tendency observed in children who reported pre-injury difficulties for exhibiting lower general memory scores than those that did not reported pre-injury difficulties. These nonsignificant findings could be related to decreased statistical power, given the reduced sample size, or alternatively to the use of a very global marker of pre-injury functioning in this study. Furthermore, the criterion "having stayed back at school or having required help at school" could only be rated for school-aged children, and also depended on the school environment and interactions between parents and school staff. A standardized measure of everyday pre-injury functioning would have been more relevant. In this study, age at injury was not associated with 7years memory function, consistently with results reported at 3,12 , and 24 months post-injury in the same cohort [12]. A negative effect of younger age at injury on memory outcomes has been reported [8], but not in all studies (see for example [53,78]). A literature review [28] reported a lack of association between age at injury and recovery of memory function over time, and suggested that the effects of age at injury could be masked by a preponderant effect of time since injury and TBI severity. Indeed, we found a strong effect of time since injury on memory recovery, with worse general memory scores at 7-years post-injury than at 1-year post-injury. This is concordant with other findings reported for verbal and visual memory, and working memory $[8,25,43]$, who found larger deficits related to a longer time post-injury, suggesting decline of memory functioning over time. 
Regarding other family/environmental factors in this study, we used the level of parental education as a proxy for socio-economic status, along with other family factors (e.g., family size) and a measure of family functioning (FAD questionnaire). Parental education was marginally associated with memory outcome at 1-year post-injury [12], but no longer at the 7-year followup, similarly to findings on prospective memory functioning in the same cohort at the same timepoint [47], or with a study on autobiographical memory [81]. Further, we found no significant association of family functioning with 7-year memory function. Environmental and family factors could have less effect on memory function than on the development of other cognitive functions (e.g., general knowledge, verbal reasoning, extent of vocabulary), however other reports highlight the role of pre-injury functioning and social disadvantage on memory outcomes [45]. Factors related to healthcare systems and rehabilitation after severe TBI may interfere with family/environmental factors on long-term cognitive outcomes (in France, regardless of socioeconomic status, children have access to care and rehabilitation when needed).

Importantly, this study highlighted associations of memory function with other previous and concurrent TBI outcomes. First, the General Memory Score was strongly correlated with concurrent intellectual ability indices, confirming that memory and other more general cognitive skills are closely interdependent, as reported in previous studies $[45,81]$. Scores included in intellectual ability measurement include verbal and visual-spatial skills but also processing speed and working memory skills, which are indicators of how efficiently children can take in, process and manage information. These skills are necessary for efficient information encoding, storage and retrieval. Moreover, it has been demonstrated that long term cognitive outcomes (including memory) were best predicted by post-acute cognitive functioning in moderate to severe TBI [46]. A relatively new finding includes the importance of broad markers of overall disability and functional impairment measured 1-year post-injury, in predicting long-term memory outcome. 
Indeed, the general memory score measured 7-years post-injury was highly correlated to a number of 1-year post-injury outcomes, including the general memory score and intellectual ability, which is expected in the context of severe brain injury. Broader measures of disability and functional impairment (GOS-Peds and PIFOS) were also highly correlated to 7-year memory outcome, and the results of the regression analysis indicated that together, those markers explained $74 \%$ of the variance of the 7-year memory score, with the GOS-Peds being the most predictive. The GOS-Peds is a broad measure of disability that considers motor and cognitive deficits and their repercussions on everyday life and the need for in- and/or outpatient rehabilitation. As reported by Neumane et al. [54] in an earlier follow-up of the TGE cohort, the overall disability and functional impairment of the patients in the TGE cohort were relatively severe at 1-year post-injury, with $30 \%$ of the children still attending a specialized rehabilitation setting, and $9 \%$ who had been referred to a special education institute. Functional outcome and disability were highly correlated to each other, and were also both highly correlated to markers of injury severity, on one hand, and to a number of clinician-measured outcomes (motor deficit, intellectual ability, educational outcome), and to standardized parent-reports of executive functioning and behavior on the other hand. Results of our study suggest that the status of the child at 1-year post-severe TBI is a very strong predictor of outcome several years later. Thus, intensive rehabilitation programs should be provided to all children who present severe functional status at discharge from intensive care, followed by systematic long-term follow-up after discharge from rehabilitation. This follow-up should probably be monitored more closely for those who still present significant disability and functional impairments at 1-year post-injury. Overall disability and functional status at 1-year post-injury seem to reflect more severe brain injury and greater vulnerability/higher risk for unfavorable outcome and could be used to adequately implement resources. This is crucial, as overall outcome 7-years post-injury indicates 
persistence of moderate to severe disability in almost half of the participants, and memory outcome was also highly correlated with overall intellectual ability, as well as educational outcome.

Regarding educational outcomes 7-years post-injury, $43 \%$ of the participants had required special help in the classroom, had stayed back, or had been referred to special education postinjury. At 1-year post-injury, this proportion was 38\% [54], indicating that this figure did not improve over time, confirming persistent effects of severe childhood TBI on education and new learning. In the early phase of follow-up, type of education was significantly associated with the general memory score measured at the same time-point [12], and our results indicate that this association was still present at the 7-year follow-up. Those results confirm deleterious effects of severe TBI on subsequent learning skills and academic achievement $[14,15,17,82]$. Obviously, academic achievement is strongly influenced by cognitive functioning (e.g., memory, executive functioning, working memory, processing speed and general intellectual ability), as those skills are necessary to efficient intake of meaningful information in the classroom $[11,14,16]$. Our results suggest that persistence of memory deficits reduced the amount of information and skills that should have been be acquired, which in turn lead to similar or even increasing difficulty in new skills understanding and mastering [81].

This study has a number of limitations. First, our findings must be considered cautiously given the small sample size, which decreased statistical power and might have prevented assessment of associations of some variables with memory function, such as pre-injury school difficulties, age at injury and parental education. Although a matched control group was included in the 7-year follow-up study (see for example $[10,12,19,51,52]$ ), this group did not perform the memory assessments, in order to reduce the burden of assessment length, and, thus, we opted not to include in the present analyses. Therefore, we relied on the robustness of the age- and gender- 
standardized norms of the memory assessment battery. However, as discussed above, the subtests used for assessment of visual and verbal memory, and the computation of composite scores differ significantly between the CMS and the WMS-IV, which only allowed us to compute and use a General Memory Score for the whole group and the longitudinal analyses. This general measure was, however, reliable (high internal consistency), which allowed its use for subsequent analyses, enabling us to draw conclusions on the evolution of general memory performance over time, but hindered more detailed analysis on the evolution and the factors associated with the memory subdomains. This highlights the importance of considering methodological issues in the assessment of outcomes, especially in studies following pediatric populations across several age spans.

Overall, the large age range at injury (3 months to 15 years) in this study made it challenging, at each stage of the study, to include tests that could apply to the whole sample. However, this large variability in age at injury is also a strength of the study, allowing assessment of the effects of age at injury on various outcomes.

Another limitation was the number of participants who did not participate to the 7-year follow-up assessment. However, a $60 \%$ retention rate at 7 years is relatively high, especially taking into account that one third of the group had reached adult age. The fact that no difference was found between participants and non-participants for any of the demographic factors, injury severity measures, and 3-, 12-, and 24-month outcomes (including memory scores), allows to reasonably assume that the sample assessed was representative of the whole sample.

Also, this study was designed to measure a number of outcomes post-severe TBI. Most children received individually tailored rehabilitation interventions (intensive in- or out-patient care) in the initial phase post-injury, and during subsequent follow-up, according to their needs. Some of 
those interventions were aimed at improving memory, but the study design did not allow assessing the specific impact of such interventions on subsequent memory functioning. Finally, brain imaging was performed for clinical purposes but was not systematically analyzed and integrated in the database, which did not allow analysis of relationships between memory performance, and brain lesions characteristics. Such analyses would have been very useful to support current researches about neural circuits of memory [29,38,83,84].

\section{Clinical implications}

Our findings underline the importance of developing instruments that can be compared across several age spans (standardization from 5 to 18 years). Long-term outcomes can be worse than expected when only considering 2-year memory outcomes which might be dependent on testretest effects. Hence, long-term follow-up beyond 2-years post-injury should be considered for children who sustained severe TBI. Persistence of cognitive impairments, impaired functional status and moderate to severe disability levels 1-year post-injury level could signposted as a red flag, suggesting higher risk of long-term impairment, requiring closer monitoring of follow-up. This, in turn, should lead to implementing tailored individualized interventions when needed.

\section{Conclusions}

Overall, we report significant, albeit highly variable memory impairment following severe childhood TBI. Despite apparent improvement over the first 2-years post-injury [12], significant impairment is still present at 7 years (with levels very similar to the initial 3-month post-injury assessment). Main factors associated with long-term memory outcomes include mostly markers of initial TBI severity, while none of the demographic, pre-injury status or environmental factors was significantly associated with memory. One important new finding is the prediction of the 7years memory function level by a number of 1-year post-injury outcomes, including relatively obvious outcomes, such as memory function and intellectual ability (reflecting overall 
neuropsychological impairments), but also more global measures of disability and functional impairments (GOS-Peds and PIFOS). As reported previously and as expected, memory function was still related with the type of education several years post-injury, suggesting ongoing consequences on new learning of cognitive deficits, including memory function. Children who sustained severe TBI should be monitored over time (until transition to adult services) and undergo comprehensive, repeated neuropsychological assessments, including memory evaluation, in order to assess strengths and weaknesses and to plan adequate and timely rehabilitation interventions and school adaptations. 


\section{References}

[1] Schneier AJ, Shields BJ, Hostetler SG, Xiang H, Smith GA. Incidence of Pediatric Traumatic Brain Injury and Associated Hospital Resource Utilization in the United States. PEDIATRICS 2006;118:483-92. https://doi.org/10.1542/peds.2005-2588.

[2] Bernier RA, Hillary FG. Traumatic brain injury and frontal lobe plasticity. Handb. Clin. Neurol., vol. 163, Elsevier; 2019, p. 411-31. https://doi.org/10.1016/B978-0-12-8042816.00022-7.

[3] Wilson L, Stewart W, Dams-O'Connor K, Diaz-Arrastia R, Horton L, Menon DK, et al. The chronic and evolving neurological consequences of traumatic brain injury. Lancet Neurol 2017;16:813-25. https://doi.org/10.1016/S1474-4422(17)30279-X.

[4] Dewan, Mummareddy N, Wellons JC, Bonfield CM. Epidemiology of Global Pediatric Traumatic Brain Injury: Qualitative Review. World Neurosurg 2016;91:497-509.e1. https://doi.org/10.1016/j.wneu.2016.03.045.

[5] Thurman. The Epidemiology of Traumatic Brain Injury in Children and Youths: A Review of Research Since 1990. J Child Neurol 2016;31:20-7. https://doi.org/10.1177/0883073814544363.

[6] Teasdale G, Jennett B. Assessment of coma and impaired consciousness. A practical scale. Lancet Lond Engl 1974;2:81-4.

[7] Massagli, Michaud LJ, Rivara FP. Association between injury indices and outcome after severe traumatic brain injury in children. Arch Phys Med Rehabil 1996;77:125-32.

[8] Babikian, Asarnow. Neurocognitive outcomes and recovery after pediatric TBI: Metaanalytic review of the literature. Neuropsychology 2009;23:283-96. https://doi.org/10.1037/a0015268.

[9] Chevignard M, Câmara-Costa H, Dellatolas G. Pediatric traumatic brain injury and abusive head trauma. Handb. Clin. Neurol., vol. 173, Elsevier; 2020, p. 451-84. https://doi.org/10.1016/B978-0-444-64150-2.00032-0.

[10] Le Fur C, Câmara-Costa H, Francillette L, Opatowski M, Toure H, Brugel D, et al. Executive functions and attention 7years after severe childhood traumatic brain injury: Results of the Traumatisme Grave de l'Enfant (TGE) cohort. Ann Phys Rehabil Med 2019. https://doi.org/10.1016/j.rehab.2019.09.003.

[11] Phillips, Parry L, Mandalis A, Lah S. Working memory outcomes following traumatic brain injury in children: A systematic review with meta-analysis. Child Neuropsychol J Norm Abnorm Dev Child Adolesc 2017;23:26-66. https://doi.org/10.1080/09297049.2015.1085500.

[12] Viot S, Câmara-Costa H, Laurence W, Francillette L, Toure H, Brugel D, et al. Assessment of memory functioning over two years following severe childhood traumatic brain injury: results of the TGE cohort. Brain Inj 2019;33:1208-18. https://doi.org/10.1080/02699052.2019.1631485.

[13] Volpe, Oliveira NCAC, Santos AC, Linhares MBM, Carlotti APCP. Neuropsychological outcome of children with traumatic brain injury and its association with late magnetic resonance imaging findings: A cohort study. Brain Inj 2017;31:1689-94. https://doi.org/10.1080/02699052.2017.1358398.

[14] Arnett, Peterson RL, Kirkwood MW, Taylor HG, Stancin T, Brown TM, et al. Behavioral and Cognitive Predictors of Educational Outcomes in Pediatric Traumatic Brain Injury. J Int Neuropsychol Soc 2013;19:881-9. https://doi.org/10.1017/S1355617713000635. 
[15] Ewing-Cobbs, Prasad MR, Kramer L, Cox CS, Baumgartner J, Fletcher S, et al. Late intellectual and academic outcomes following traumatic brain injury sustained during early childhood. J Neurosurg 2006;105:287-96. https://doi.org/10.3171/ped.2006.105.4.287.

[16] Fulton JB, Yeates KO, Taylor HG, Walz NC, Wade SL. Cognitive predictors of academic achievement in young children 1 year after traumatic brain injury. Neuropsychology 2012;26:314-22. https://doi.org/10.1037/a0027973.

[17] Kingery, Narad ME, Taylor HG, Yeates KO, Stancin T, Wade SL. Do Children Who Sustain Traumatic Brain Injury in Early Childhood Need and Receive Academic Services 7 Years After Injury?: J Dev Behav Pediatr 2017;38:728-35. https://doi.org/10.1097/DBP.0000000000000489.

[18] Câmara-Costa H, Francillette L, Opatowski M, Toure H, Brugel D, Laurent-Vannier A, et al. Participation seven years after severe childhood traumatic brain injury. Disabil Rehabil 2019:1-10. https://doi.org/10.1080/09638288.2019.1594398.

[19] Câmara-Costa H, Opatowski M, Francillette L, Toure H, Brugel D, Laurent-Vannier A, et al. Self- and parent-reported Quality of Life 7 years after severe childhood traumatic brain injury in the Traumatisme Grave de l'Enfant cohort: associations with objective and subjective factors and outcomes. Qual Life Res Int J Qual Life Asp Treat Care Rehabil 2019. https://doi.org/10.1007/s11136-019-02305-7.

[20] de Kloet, Gijzen R, Braga LW, Meesters JJL, Schoones JW, Vliet Vlieland TPM. Determinants of participation of youth with acquired brain injury: A systematic review. Brain Inj 2015:1-11. https://doi.org/10.3109/02699052.2015.1034178.

[21] Di Battista A, Soo C, Catroppa C, Anderson V. Quality of Life in Children and Adolescents Post-TBI: A Systematic Review and Meta-Analysis. J Neurotrauma 2012;29:1717-27. https://doi.org/10.1089/neu.2011.2157.

[22] Tulving E. Episodic Memory: From Mind to Brain. Annu Rev Psychol 2002;53:1-25. https://doi.org/10.1146/annurev.psych.53.100901.135114.

[23] Lah, Epps A, Levick W, Parry L. Implicit and explicit memory outcome in children who have sustained severe traumatic brain injury: Impact of age at injury (preliminary findings). Brain Inj 2011;25:44-52. https://doi.org/10.3109/02699052.2010.531693.

[24] Lah, Gott C, Epps A, Parry L. Imagining the future in children with severe traumatic brain injury. J Neurotrauma 2018. https://doi.org/10.1089/neu.2017.5250.

[25] Gorman, Barnes MA, Swank PR, Ewing-Cobbs L. Recovery of Working Memory Following Pediatric Traumatic Brain Injury: A Longitudinal Analysis. Dev Neuropsychol 2017;42:127-45. https://doi.org/10.1080/87565641.2017.1315581.

[26] Gorman S, Barnes MA, Swank PR, Prasad M, Ewing-Cobbs L. The Effects of Pediatric Traumatic Brain Injury on Verbal and Visual-Spatial Working Memory. J Int Neuropsychol Soc 2012;18:29-38. https://doi.org/10.1017/S1355617711001251.

[27] Lah, Black C, Gascoigne MB, Gott C, Epps A, Parry L. Accelerated Long-Term Forgetting Is Not Epilepsy Specific: Evidence from Childhood Traumatic Brain Injury. J Neurotrauma 2017;34:2536-44. https://doi.org/10.1089/neu.2016.4872.

[28] Babikian, Merkley T, Savage RC, Giza CC, Levin H. Chronic Aspects of Pediatric Traumatic Brain Injury: Review of the Literature. J Neurotrauma 2015;32:1849-60. https://doi.org/10.1089/neu.2015.3971.

[29] DeMaster, Johnson C, Juranek J, Ewing-Cobbs L. Memory and the hippocampal formation following pediatric traumatic brain injury. Brain Behav 2017;7:e00832. https://doi.org/10.1002/brb3.832. 
[30] Königs M, van Heurn LWE, Bakx R, Vermeulen RJ, Goslings JC, Poll-The BT, et al. The structural connectome of children with traumatic brain injury: The Connectome after Pediatric TBI. Hum Brain Mapp 2017. https://doi.org/10.1002/hbm.23614.

[31] Königs M, Pouwels PJ, Ernest van Heurn L, Bakx R, Jeroen Vermeulen R, Carel Goslings J, et al. Relevance of neuroimaging for neurocognitive and behavioral outcome after pediatric traumatic brain injury. Brain Imaging Behav 2018;12:29-43. https://doi.org/10.1007/s11682-017-9673-3.

[32] Mayes A, Isaac C, Holdstock J, Cariga P, Gummer A, Roberts N. Long-Term Amnesia: A Review and Detailed Illustrative Case Study. Cortex 2003;39:567-603. https://doi.org/10.1016/S0010-9452(08)70855-4.

[33] McAuley T, Chen S, Goos L, Schachar R, Crosbie J. Is the behavior rating inventory of executive function more strongly associated with measures of impairment or executive function? J Int Neuropsychol Soc 2010;16:495-505.

[34] Chevignard M, Kerrouche B, Krasny-Pacini A, Mariller A, Pineau-Chardon E, Notteghem $\mathrm{P}$, et al. Ecological Assessment of Everyday Executive Functioning at Home and at School Following Childhood Traumatic Brain Injury Using the BRIEF Questionnaire. J Head Trauma Rehabil 2017;32:E1-12. https://doi.org/10.1097/HTR.0000000000000295.

[35] Dollman AK, Figaji AA, Schrieff-Elson LE. Academic and Behavioral Outcomes in School-Age South African Children Following Severe Traumatic Brain Injury. Front Neuroanat 2017;11:121. https://doi.org/10.3389/fnana.2017.00121.

[36] Catroppa, Anderson. Recovery in memory function in the first year following TBI in children. Brain Inj 2002;16:369-84. https://doi.org/10.1080/02699050110104444.

[37] Max, Roberts MA, Koele SL, Lindgren SD, Robin DA, Arndt S, et al. Cognitive outcome in children and adolescents following severe traumatic brain injury: influence of psychosocial, psychiatric, and injury-related variables. J Int Neuropsychol Soc JINS 1999;5:58-68.

[38] Verger K, Serra-Grabulosa JM, Junqué C, Alvarez A, Bartrés-Faz D, Mercader JM. [Study of the long term sequelae of traumatic brain injury: evaluation of declarative and procedural memory, and its neuroanatomic substrate]. Rev Neurol 2001;33:30-4.

[39] Silberg T, Ahonniska-Assa J, Levav M, Eliyahu R, Peleg-Pilowsky T, Brezner A, et al. The effect of age-at-testing on verbal memory among children following severe traumatic brain injury. Child Neuropsychol 2016;22:600-17.

https://doi.org/10.1080/09297049.2015.1028348.

[40] Ewing-Cobbs L, Fletcher JM, Levin HS, Francis DJ, Davidson K, Miner ME. Longitudinal neuropsychological outcome in infants and preschoolers with traumatic brain injury. J Int Neuropsychol Soc JINS 1997;3:581-91.

[41] King DJ, Ellis KR, Seri S, Wood AG. A systematic review of cross-sectional differences and longitudinal changes to the morphometry of the brain following paediatric traumatic brain injury. NeuroImage Clin 2019;23:101844. https://doi.org/10.1016/j.nicl.2019.101844.

[42] Yeates KO, Taylor HG, Wade SL, Drotar D, Stancin T, Minich N. A prospective study of short- and long-term neuropsychological outcomes after traumatic brain injury in children. Neuropsychology 2002;16:514-23. https://doi.org/10.1037/0894-4105.16.4.514.

[43] Dunning, Westgate B, Adlam A-LR. A meta-analysis of working memory impairments in survivors of moderate-to-severe traumatic brain injury. Neuropsychology 2016;30:811-9. https://doi.org/10.1037/neu0000285.

[44] Anderson, Morse SA, Catroppa C, Haritou F, Rosenfeld JV. Thirty month outcome from early childhood head injury: a prospective analysis of neurobehavioural recovery. Brain $\mathrm{J}$ Neurol 2004;127:2608-20. https://doi.org/10.1093/brain/awh320. 
[45] Johnson, Donders. Correlates of verbal learning and memory after pediatric traumatic brain injury. Appl Neuropsychol Child 2017:1-8. https://doi.org/10.1080/21622965.2017.1330688.

[46] Moran, Babikian T, Del Piero L, Ellis MU, Kernan CL, Newman N, et al. The UCLA study of Predictors of Cognitive Functioning Following Moderate/Severe Pediatric Traumatic Brain Injury. J Int Neuropsychol Soc 2016;22:512-9. https://doi.org/10.1017/S1355617716000175.

[47] Krasny-Pacini, Francillette L, Toure H, Brugel D, Laurent-Vannier A, Meyer P, et al. Prospective memory 7 years after severe childhood traumatic brain injury - the TGE 2 prospective longitudinal study. Dev Neurorehabilitation 2017;20:456-61. https://doi.org/10.1080/17518423.2016.1265605.

[48] McCauley, McDaniel MA, Pedroza C, Chapman SB, Levin HS. Incentive Effects on EventBased Prospective Memory Performance in Children and Adolescents with Traumatic Brain Injury. Neuropsychology 2009;23:201-9. https://doi.org/10.1037/a0014192.

[49] McCauley, Pedroza C, Chapman SB, Cook LG, Hotz G, VáSquez AC, et al. Event-based prospective memory performance during subacute recovery following moderate to severe traumatic brain injury in children: Effects of monetary incentives. J Int Neuropsychol Soc 2010;16:335. https://doi.org/10.1017/S135561770999138X.

[50] McCauley, Pedroza C, Chapman SB, Cook LG, Vásquez AC, Levin HS. Monetary Incentive Effects on Event-Based Prospective Memory Three Months after Traumatic Brain Injury in Children. J Clin Exp Neuropsychol 2011;33:639-46. https://doi.org/10.1080/13803395.2010.547844.

[51] Câmara-Costa H, Francillette L, Opatowski M, Toure H, Brugel D, Laurent-Vannier A, et al. Participation seven years after severe childhood traumatic brain injury. Disabil Rehabil 2019:1-10. https://doi.org/10.1080/09638288.2019.1594398.

[52] Câmara-Costa H, Francillette L, Opatowski M, Toure H, Brugel D, Laurent-Vannier A, et al. Self- and Parent-Reported Fatigue 7 Years After Severe Childhood Traumatic Brain Injury: Results of the Traumatisme Grave de l'Enfant Prospective Longitudinal Study. J Head Trauma Rehabil 2019. https://doi.org/10.1097/HTR.0000000000000502.

[53] Krasny-Pacini A, Chevignard M, Lancien S, Escolano S, Laurent-Vannier A, De Agostini M, et al. Executive function after severe childhood traumatic brain injury - Age-at-injury vulnerability periods: The TGE prospective longitudinal study. Ann Phys Rehabil Med 2017;60:74-82. https://doi.org/10.1016/j.rehab.2016.06.001.

[54] Neumane S, Camara-Costa H, Francillette L, Araujo M, Toure H, Brugel D, et al. Functional outcome after severe childhood traumatic brain injury: results of the TGE prospective longitudinal study. Ann Phys Rehabil Med 2020. https://doi.org/10.1016/j.rehab.2020.01.008.

[55] Baker SP, O’Neill B, Haddon W, Long WB. The injury severity score: a method for describing patients with multiple injuries and evaluating emergency care. J Trauma 1974;14:187-96.

[56] Carney NA, Chesnut R, Kochanek PM. Guidelines for the acute medical management of severe traumatic brain injury in infants, children, and adolescents: Pediatr Crit Care Med 2003;4:S1. https://doi.org/10.1097/01.CCM.0000067635.95882.24.

[57] Tepas JJ, Mollitt DL, Talbert JL, Bryant M. The pediatric trauma score as a predictor of injury severity in the injured child. J Pediatr Surg 1987;22:14-8. 
[58] Wilson JTL, Pettigrew LEL, Teasdale GM. Structured Interviews for the Glasgow Outcome Scale and the Extended Glasgow Outcome Scale: Guidelines for Their Use. J Neurotrauma 1998;15:573-85. https://doi.org/10.1089/neu.1998.15.573.

[59] Ewing-Cobbs L, Bloom DR, Prasad MR, Waugh JK, Cox CS, Swank PR. Assessing recovery and disability after physical trauma: the Pediatric Injury Functional Outcome Scale. J Pediatr Psychol 2014;39:653-65. https://doi.org/10.1093/jpepsy/jsu018.

[60] Wechsler D. Échelle d'intelligence de Wechsler pour enfants: WISC-III. Paris, France: Les Éditions du Centre de Psychologie Appliquée; 1996.

[61] Wechsler D. WPPSI-III échelle d'Intelligence de Wechsler pour la période préscolaire et primaire : Manuel d'administration et de cotation; Manuel d'interprétation; Livre de stimuli 1 ; Livre de stimuli 2. Les Éditions du Centre de Psychologie Appliquée. Paris, France: Les Éditions du Centre de Psychologie Appliquée; 2002.

[62] Cohen. CMS: échelle de mémoire pour enfants. ECPA, les Éditions du Centre de psychologie appliquée. Paris: 2001.

[63] Monahan. Children's Memory Scale, by M. Cohen. San Antonio, TX Psychological Corporation, 1997. Arch Clin Neuropsychol 2001;16:193-8. https://doi.org/10.1016/S08876177(99)00064-5.

[64] Beers, Wisniewski SR, Garcia-Filion P, Tian Y, Hahner T, Berger RP, et al. Validity of a Pediatric Version of the Glasgow Outcome Scale-Extended. J Neurotrauma 2012;29:112639. https://doi.org/10.1089/neu.2011.2272.

[65] Wechsler D. MEM-IV, Échelle clinique de mémoire de Wechsler: manuel d'interprétation. Montreuil: ECPA : Pearson; 2012.

[66] Wechsler D. Échelle d'intelligence de Wechsler pour enfants: WISC-IV. Paris, France: Les Éditions du Centre de Psychologie Appliquée; 2005.

[67] Wechsler D. Échelle d'intelligence de Wechsler pour adultes WAIS-IV. Paris: Les Éditions du Centre de Psychologie Appliquée; 2008.

[68] Gioia GA, Isquith PK, Guy SC, Kenworthy L. BRIEF: Inventaire d'évaluation comportementale des fonctions exécutives [BRIEF: Behavior rating inventory of executive function]. Paris, France: Hogrefe; 2014.

[69] Roth RM, Gioia GA, Isquith PK. BRIEF-A: Inventaire d'évaluation comportementale des fonctions exécutives - version adulte [BRIEF-A: behavior rating inventory of executive function - adult version]. Paris, France: Hogrefe; 2015.

[70] Achenbach TM, Rescorla LA. Manual for the ASEBA school-age forms \& profiles. Burlington, VT: University of Vermont: Research Center for Children, Youth, \& Families; 2001.

[71] Achenbach TM, Rescorla LA. Manual for the ASEBA adult forms \& profiles. Burlington, VT: University of Vermont: Research Center for Children, Youth, \& Families; 2003.

[72] Varni JW, Seid M, Rode CA. The PedsQL: measurement model for the pediatric quality of life inventory. Med Care 1999;37:126-39.

[73] Varni JW, Limbers CA. The PedsQL 4.0 Generic Core Scales Young Adult Version: feasibility, reliability and validity in a university student population. J Health Psychol 2009;14:611-22. https://doi.org/10.1177/1359105309103580.

[74] Varni JW, Burwinkle TM, Katz ER, Meeske K, Dickinson P. The PedsQL in pediatric cancer: reliability and validity of the Pediatric Quality of Life Inventory Generic Core Scales, Multidimensional Fatigue Scale, and Cancer Module. Cancer 2002;94:2090-106. https://doi.org/10.1002/cncr.10428. 
[75] Varni JW, Limbers CA. The PedsQL Multidimensional Fatigue Scale in young adults: feasibility, reliability and validity in a University student population. Qual Life Res Int J Qual Life Asp Treat Care Rehabil 2008;17:105-14. https://doi.org/10.1007/s11136-0079282-5.

[76] Boterhoven de Haan KL, Hafekost J, Lawrence D, Sawyer MG, Zubrick SR. Reliability and validity of a short version of the general functioning subscale of the McMaster Family Assessment Device. Fam Process 2015;54:116-23. https://doi.org/10.1111/famp.12113.

[77] Speranza M, Guénolé F, Revah-Levy A, Egler P-J, Negadi F, Falissard B, et al. The French version of the Family Assessment Device. Can J Psychiatry Rev Can Psychiatr 2012;57:570-7. https://doi.org/10.1177/070674371205700908.

[78] Tavano, Galbiati S, Recla M, Bardoni A, Dominici C, Pastore V, et al. Cognitive recovery after severe traumatic brain injury in children/adolescents and adults: Similar positive outcome but different underlying pathways? Brain Inj 2014;28:900-5. https://doi.org/10.3109/02699052.2014.890742.

[79] Anderson V, Godfrey C, Rosenfeld JV, Catroppa C. Predictors of cognitive function and recovery 10 years after traumatic brain injury in young children. Pediatrics 2012;129:e254261. https://doi.org/10.1542/peds.2011-0311.

[80] Catroppa C, Anderson VA, Morse SA, Haritou F, Rosenfeld JV. Outcome and predictors of functional recovery 5 years following pediatric traumatic brain injury (TBI). J Pediatr Psychol 2008;33:707-18. https://doi.org/10.1093/jpepsy/jsn006.

[81] Lah, Gott C, Parry L, Black C, Epps A, Gascoigne M. Selective, age-related autobiographical memory deficits in children with severe traumatic brain injury. J Neuropsychol 2017. https://doi.org/10.1111/jnp.12141.

[82] Kinsella, Prior M, Sawyer M, Ong B, Murtagh D, Eisenmajer R, et al. Predictors and indicators of academic outcome in children 2 years following traumatic brain injury. J Int Neuropsychol Soc JINS 1997;3:608-16.

[83] McCauley, Wilde EA, Merkley TL, Schnelle KP, Bigler ED, Hunter JV, et al. Patterns of Cortical Thinning in Relation to Event-Based Prospective Memory Performance Three Months after Moderate to Severe Traumatic Brain Injury in Children. Dev Neuropsychol 2010;35:318-32. https://doi.org/10.1080/87565641003696866.

[84] Paterno, Folweiler KA, Cohen AS. Pathophysiology and Treatment of Memory Dysfunction After Traumatic Brain Injury. Curr Neurol Neurosci Rep 2017;17:52. https://doi.org/10.1007/s11910-017-0762-x. 
Table 1. Sociodemographic characteristics, pre-injury education, injury severity and injury-related outcomes 1- and 7- years after severe childhood Traumatic Brain Injury.

\begin{tabular}{|c|c|}
\hline & $\begin{array}{c}\text { Severe TBI } \\
(n=37)\end{array}$ \\
\hline \multicolumn{2}{|l|}{ Sociodemographic characteristics at the 7-year follow-up } \\
\hline Age (years): Mean (SD) [Range] & $15.42(4.44)[7.42-22.7]$ \\
\hline Time since injury (years): Mean (SD) [Range] & $7.82(.86)[5.92-9.33]$ \\
\hline Gender (male): n (\%) & $23(62)$ \\
\hline Parental education (at least one parent graduated from high school) & $19(51)$ \\
\hline Family situation (non-marital or single parent) & $12(32)$ \\
\hline Family size (> 2 children in the household) & $28(76)$ \\
\hline \multicolumn{2}{|l|}{ Pre-injury education } \\
\hline Assisted and/or Delayed & $5(14)$ \\
\hline \multicolumn{2}{|l|}{ Initial Injury Severity } \\
\hline Age at injury (years) & $7.61(4.55)[.25-14.67]$ \\
\hline Lowest Glasgow Coma Scale Score & $5.92(1.66)[3-8]$ \\
\hline Pediatric Trauma Score & $3.87(2.28)[-1-+9]$ \\
\hline Injury Severity Score & $27.57(10.07)[4-50]$ \\
\hline Length of coma (days) & $6.49(4.96)[1-22]$ \\
\hline \multicolumn{2}{|l|}{ Injury-related characteristics } \\
\hline Intracranial Hypertension (yes) & $10(29)$ \\
\hline Brain hypo perfusion (yes) & $29(83)$ \\
\hline Collapses (yes) & $6(16)$ \\
\hline Seizures (yes) & $3(8)$ \\
\hline Penetrating skull fracture (yes) & $7(19)$ \\
\hline \multicolumn{2}{|l|}{ 1-year post-injury outcomes } \\
\hline \multicolumn{2}{|l|}{ Overall disability (GOS Peds) } \\
\hline Good Recovery & $5(14)$ \\
\hline Moderate Disability & $20(54)$ \\
\hline Severe Disability & $12(32)$ \\
\hline Motor deficits (yes) & $13(35)$ \\
\hline \multicolumn{2}{|l|}{ Ongoing education } \\
\hline Not attending (children $<3$ years) & $4(11)$ \\
\hline Mainstream & $14(38)$ \\
\hline Specialized/mainstream with adaptations & $19(51)$ \\
\hline Functional outcome (PIFOS score, $n=31$ ) & $27.61(16.81)[4-73]$ \\
\hline Intellectual ability (FSIQ - Wechsler scales, $n=35$ ) & $88.91(18.54)[48-136]$ \\
\hline General memory (CMS - Wechsler scales, $n=24$ ) & $96.54(21.54)[66-136]$ \\
\hline \multicolumn{2}{|l|}{ 7-years post-injury outcomes } \\
\hline \multicolumn{2}{|l|}{ Overall disability (GOS-E/GOS-E Peds) } \\
\hline Good Recovery & $21(57)$ \\
\hline Moderate Disability & $9(24)$ \\
\hline Severe Disability & $7(19)$ \\
\hline Motor deficits (yes) & $8(22)$ \\
\hline \multicolumn{2}{|l|}{ Ongoing education } \\
\hline Mainstream & $21(57)$ \\
\hline Specialized/mainstream with adaptations & $16(43)$ \\
\hline Intellectual ability (FSIQ - Wechsler scales, $n=36$ ) & $86.39(18.00)[40-129]$ \\
\hline
\end{tabular}

TBI: Traumatic Brain Injury; SD: Standard Deviation; GOS Peds: Pediatric Glasgow Outcome Scale; PIFOS: Pediatric Injury Functional Outcome; FSIQ: Full Scale Intellectual Quotient; CMS: Children's Memory Scale; GOSE/GOS-E Peds: Glasgow Outcome Scale-Extended/Glasgow Outcome Scale-Extended, Pediatric version. 
Table 2. Memory domains performance 7-years after severe childhood Traumatic Brain Injury ( $n=37)$.

\begin{tabular}{|c|c|c|c|c|c|c|c|c|c|c|c|c|c|c|c|c|}
\hline & \multicolumn{7}{|c|}{$\begin{array}{c}\text { Children's Memory Scale (CMS) } \\
\text { (ages }<16 \text { years) }\end{array}$} & \multicolumn{7}{|c|}{$\begin{array}{c}\text { Wechsler Memory Scale (WMS)-IV } \\
\text { (ages } \geq 16 \text { years) }\end{array}$} & \multirow[b]{2}{*}{$t$} & \multirow[b]{2}{*}{$p$} \\
\hline & $\mathbf{N}$ & $\mathbf{M}$ & SD & Min & Max & $<1 \mathrm{SD}$ & $<2$ SD & $\mathbf{N}$ & $\mathbf{M}$ & SD & Min & Max & $<1 \mathrm{SD}$ & $<2$ SD & & \\
\hline General Memory & 20 & 84.30 & 16.43 & 50 & 119 & $50 \%$ & $15 \%$ & 17 & 85.01 & 10.85 & 67 & 104.75 & $59 \%$ & $18 \%$ & -.15 & .879 \\
\hline Visual Immediate Memory & 20 & 91.05 & 14.15 & 63 & 113 & $40 \%$ & $10 \%$ & 17 & 79.65 & 20.49 & 40 & 110 & $53 \%$ & $29 \%$ & 1.99 & .054 \\
\hline Visual Delayed Memory & 20 & 93.35 & 13.61 & 59 & 113 & $20 \%$ & $10 \%$ & 17 & 70.12 & 14.35 & 45 & 100 & $88 \%$ & $47 \%$ & 5.05 & $<.0001$ \\
\hline Verbal Immediate Memory & 20 & 83.70 & 20.36 & 50 & 130 & $55 \%$ & $20 \%$ & 17 & 90.53 & 23.61 & 40 & 135 & $29 \%$ & $18 \%$ & -.95 & .351 \\
\hline Verbal Delayed Memory & 20 & 83.90 & 20.58 & 50 & 130 & $60 \%$ & $25 \%$ & 17 & 92.26 & 18.79 & 45 & 125 & $18 \%$ & $6 \%$ & -1.28 & .209 \\
\hline
\end{tabular}

At 7-years post-injury, patients were assessed according to age with the CMS (age<16 years) or the WMS-IV (age >16 years). WMS-IV: Wechsler Memory Scale $4^{\text {th }}$ edition; M: Mean; SD: Standard Deviation; Min: Minimum; Max: Maximum. 
Table 3. Associations of the general memory score 7- years after severe childhood Traumatic Brain Injury with injury severity and 1-year post-injury outcomes

\begin{tabular}{lccc}
\hline & \multicolumn{2}{c}{ General memory 7-years post severe TBI } \\
\cline { 2 - 3 } & $\boldsymbol{n}$ & Statistic & $\boldsymbol{p}$ \\
\hline Initial Injury Severity & & & \\
$\quad$ Age at injury & 37 & $r=-.08$ & .642 \\
$\quad$ Lowest Glasgow Coma Scale Score & 37 & $r=-.13$ & .428 \\
Pediatric Trauma Score & 37 & $r=.09$ & .604 \\
Injury Severity Score & 37 & $r=-.33$ & .041 \\
Length of coma (days) & 37 & $r=-.43$ & .009 \\
1-year post-injury outcomes & & & .0005 \\
Overall disability (GOS Peds) & 37 & $\mathrm{~F}(2,36)=9.63$ & .266 \\
Motor deficits (yes) & 37 & $t(35)=1.13$ & .0001 \\
Functional outcome (PIFOS) & 31 & $r=-.64$ & $<.0001$ \\
Intellectual ability (FSIQ) & 35 & $r=.67$ & .0003 \\
General memory (CMS) & 24 & $r=.68$ &
\end{tabular}

$r$ : Pearson correlation coefficient; $F$ : Generalized Linear Model; $t$ : Student's $t$-test; GOS Peds: Glasgow Outcome Scale, Pediatric version; PIFOS: Pediatric Injury Functional Outcome; FSIQ: Full Scale Intellectual Quotient; CMS: Children's Memory Scale. 
Table 4. Regression analyses of the general memory score 7-years post-injury from the outcomes assessed 1-year post-TBI.

\begin{tabular}{lccccc}
\hline & \multicolumn{5}{c}{ General Memory 7-years post severe TBI } \\
\cline { 2 - 6 } & $r^{2}$ & $\beta$ & $s(\beta)$ & $F$ & $p$ \\
\hline 1-year post-injury outcomes & 0.74 & & & & \\
Overall disability (GOS Peds) & & -13.57 & 3.62 & -3.75 & 0.002 \\
Motor deficits (yes) & 6.87 & 4.22 & 1.63 & 0.121 \\
Functional outcome (PIFOS) & 0.20 & 0.17 & 0.18 & 0.255 \\
Intellectual ability (FSIQ) & & 0.22 & 0.10 & 2.17 & 0.043 \\
General memory (CMS) & & 0.18 & 0.09 & 2.04 & 0.056 \\
\hline
\end{tabular}

GOS Peds: Glasgow Outcome Scale, Pediatric version; PIFOS: Pediatric Injury Functional Outcome; FSIQ: Full Scale Intellectual Quotient; CMS: Children's Memory Scale. 
Table 5. Associations of the general memory score 7- years after severe childhood Traumatic Brain Injury with concurrent "objective" outcomes.

General memory 7-years post severe TBI

\begin{tabular}{lll}
\hline$n$ & Statistic & $p$ \\
\hline
\end{tabular}

\section{7-years post-injury outcomes}

\section{Clinician-rated measures}

Overall disability (GOS-E/GOS-E Peds)

$\begin{array}{lll}37 & F(2,36)=1.66 & .205 \\ 37 & t(35)=.15 & .883\end{array}$

Motor deficits (yes)

\section{Performance-based measures}

Ongoing education

$$
37 t(35)=2.2
$$

Wechsler scales

$$
\begin{aligned}
& \text { Full Scale Intellectual Quotient } \\
& \text { Verbal Intellectual Quotient } \\
& \text { Performance Intellectual Quotient } \\
& \text { Working Memory Index } \\
& \text { Processing Speed Index }
\end{aligned}
$$

$\begin{array}{llr}36 & r=.71 & <.0001 \\ 37 & r=.62 & <.0001 \\ 37 & r & =.57 \\ 37 & r=.64 & .0003 \\ 36 & r=.57 & .0001 \\ & .0003\end{array}$

$F$ : Generalized Linear Model; $t$ : Student's t-test; $r$ : Pearson correlation coefficient; GOS-E/GOS-E Peds: Glasgow Outcome Scale-Extended/Glasgow Outcome Scale-Extended, Pediatric version. 
Table 6. Associations of the general memory score 7- years after severe childhood Traumatic Brain Injury with concurrent questionnaire-based measures.

\begin{tabular}{ccc}
\hline & \multicolumn{2}{c}{ General memory 7-years post severe TBI } \\
\cline { 2 - 3 } & $n \quad$ Statistic & $p$ \\
\hline
\end{tabular}

\section{Questionnaire-based measures}

Parent-reports

Executive Functions (BRIEF)

Behavioral Regulation Index

Metacognition Index

$30 \quad r=-20$

.292

Global Executive Composite

$30 \quad r=-.22$

.239

$30 \quad r=-.23$

.229

Behavior (CBCL/ABCL)

Internalizing problems

$32 \quad r=-.09 \quad .639$

Externalizing problems

$32 \quad r=-.42$

.018

Total problems

32

$r=-.31$

.080

Health-Related Quality of Life (PedsQL)

Total score

$24 \quad r=.08$

Fatigue (MFS)

Total score

$24 \quad r=-.04$

Family functioning (FAD)

Total score

$33 r=-.06$

Self-reports

Executive Functions (BRIEF)

Behavioral Regulation Index

$11 \quad r=-.51 \quad .108$

Metacognition Index

$11 \quad r=-.67$

.026

Global Executive Composite

$11 r=-.70$

.016

Behavior (Y/ASR)

Internalizing problems

$23 r=-.36 \quad .097$

Externalizing problems

$23 \quad r=-.29$

Total problems

23

$r=-.37$

Health-Related Quality of Life (PedsQL)

Total score

$r=.17$

Fatigue (MFS)

Total score

$33 r=.11$

.556

$r$ : Pearson correlation coefficient; BRIEF: Behavior Rating Inventory of Executive Function; CBCL: Child Behavior Checklist; ABCL: Adult Behavior Checklist; PedsQL: Pediatric Quality of Life inventory; MFS: Multidimensional Fatigue Scale; FAD: Family Assessment Device; Y/ASR: Youth/Adult Self Report. 


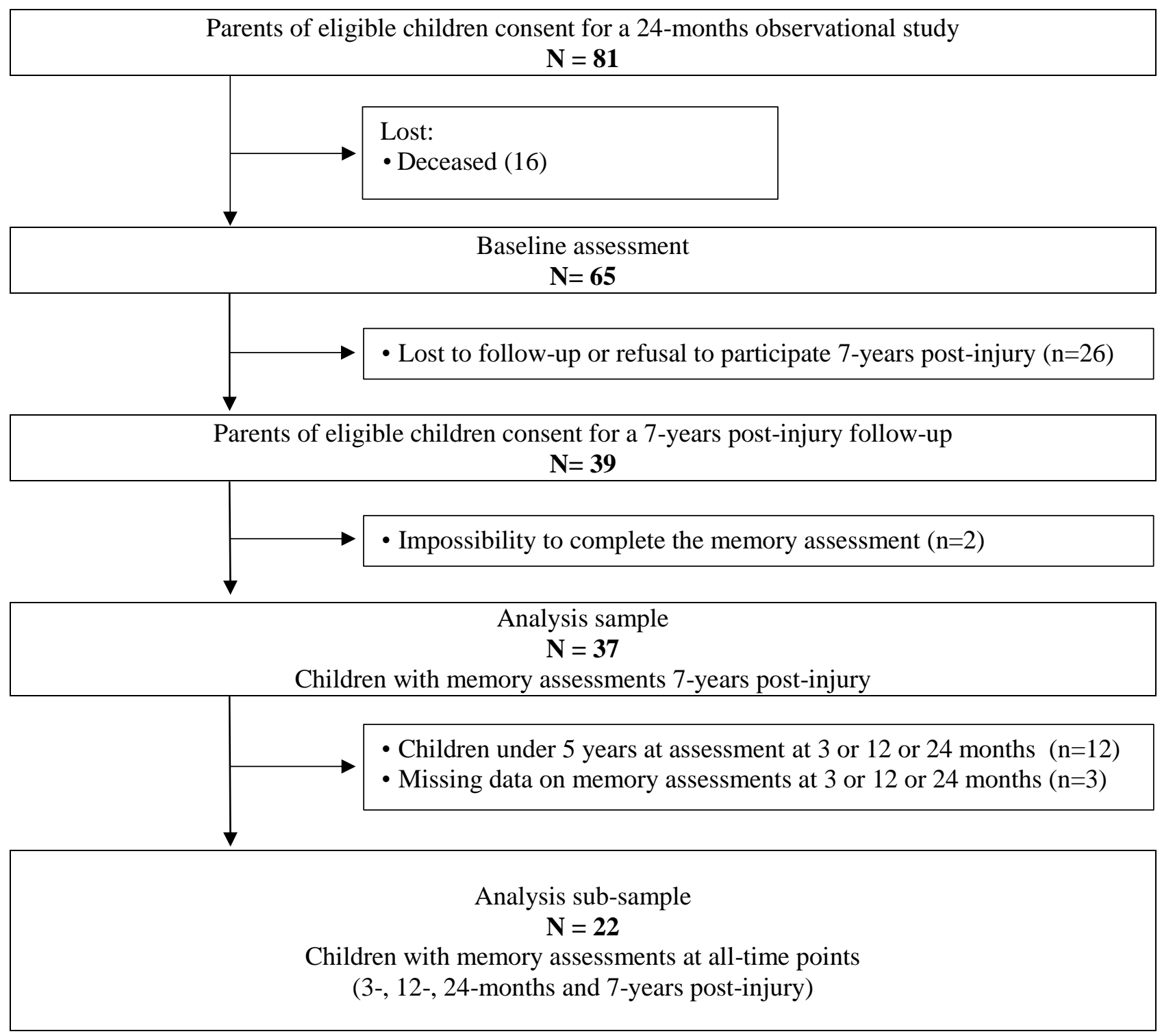

Figure 1. Flowchart: Evolution of the sample of patients included in the study (adapted from Viot et al., 2019). 


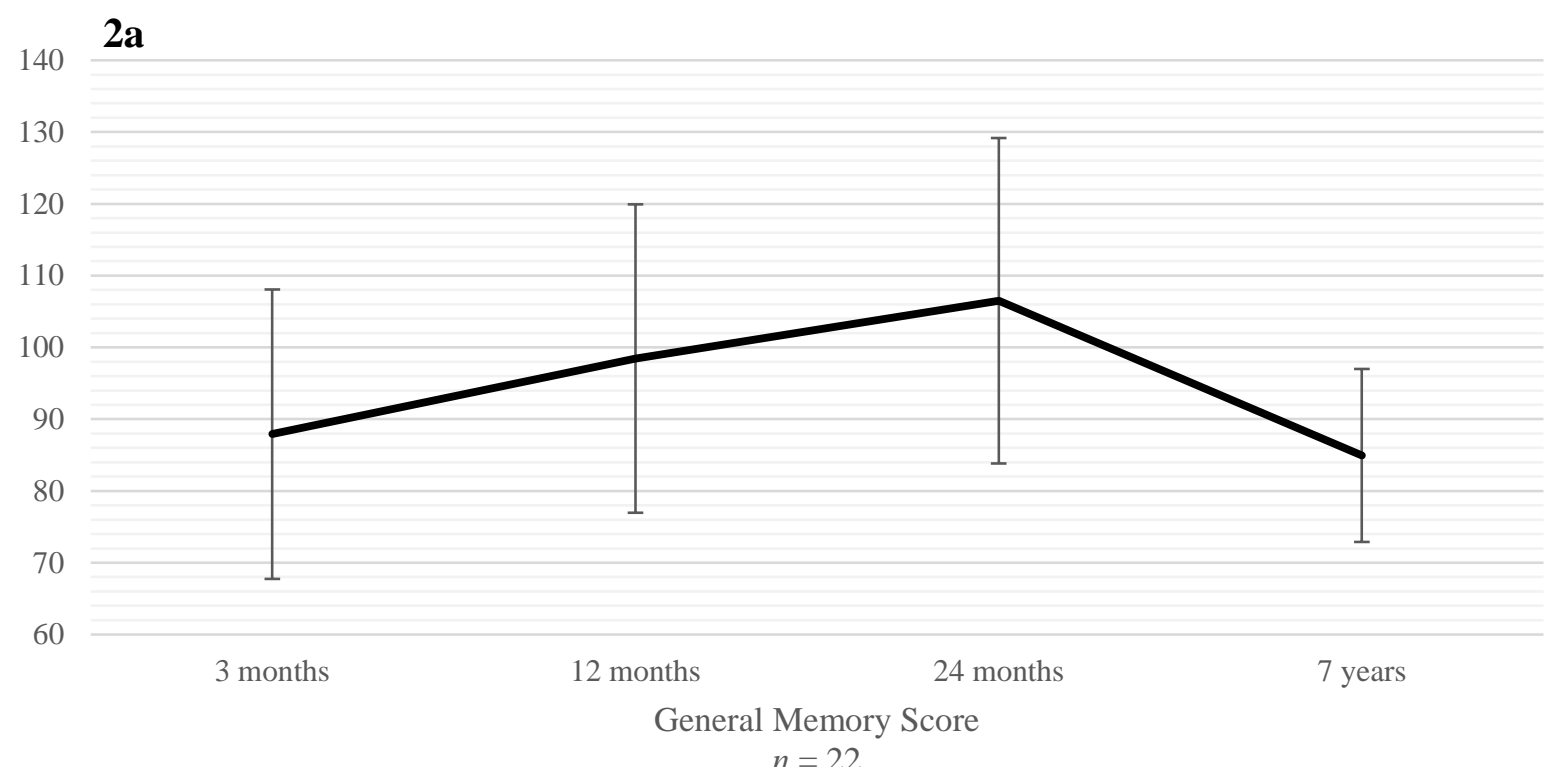

$$
n=22
$$

2b

160

140

120

100

80

60

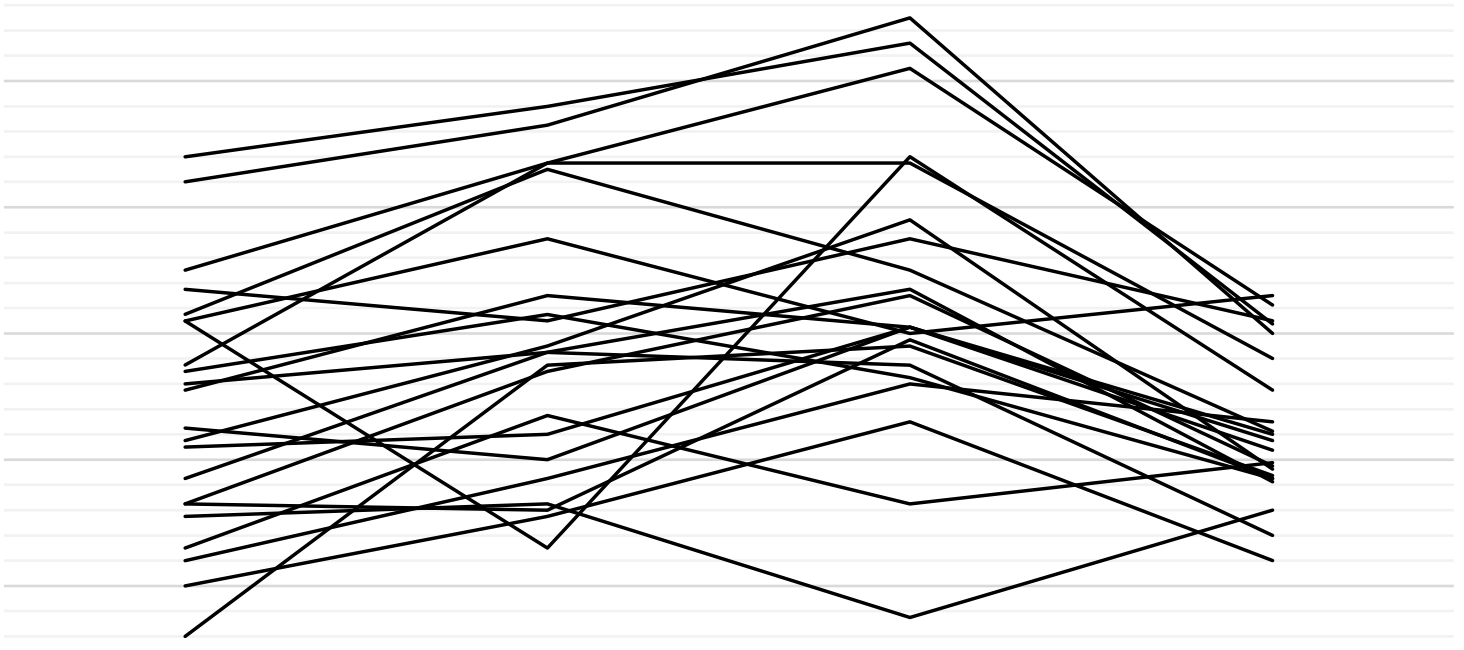

40

General Memory Score

$$
n=22
$$

Figure 2a. Evolution of the General memory mean scores at 3-, 12-, 24-months and 7-years after Traumatic Brain Injury. 2b. Evolution of the General memory mean scores at 3-, 12-, 24-months and 7-years after severe pediatric Traumatic Brain Injury, by subject $(n=22)$. 


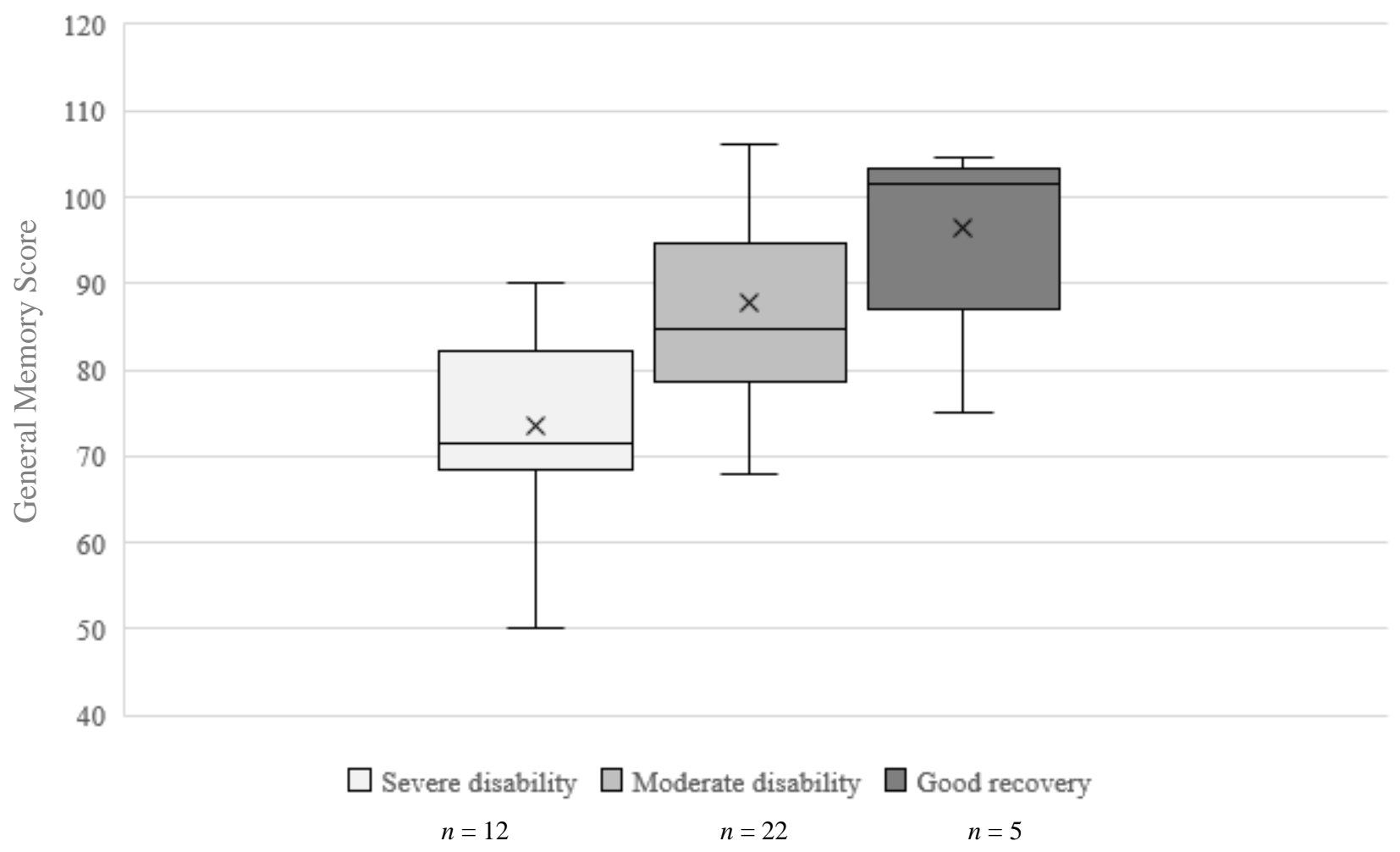

Figure 3. Distribution of the general memory scores 7-years post-injury according to overall level of disability 1-year post-injury assessed by the Glasgow Outcome Scale-Pediatric version (GOS-Peds). Mean expected memory score expected in the general population $=100(\mathrm{SD}=15)$. $\mathrm{x}$ $=$ Mean; Horizontal line $=$ Median; Vertical line $=$ Range . 